\title{
STRUCTURE, ELECTRONIC AND VIBRATIONAL STUDY OF 7-METHYL-2,3-DIHYDRO-(1,3) THIAZOLO(3,2-A)PYRIMIDIN-5-ONE BY USING DENSITY FUNCTIONAL THEORY
}

Bhawani Datt Joshi, Janga Bahadur Khadka and Atamram Bhatt

Journal of Institute of Science and Technology

Volume 22, Issue 2, January 2018

ISSN: 2469-9062 (print), 2467-9240 (e)

Editors:

Prof. Dr. Kumar Sapkota

Prof. Dr. Armila Rajbhandari

Assoc. Prof. Dr. Gopi Chandra Kaphle Mrs. Reshma Tuladhar

JIST, 22 (2): 1-11 (2018)

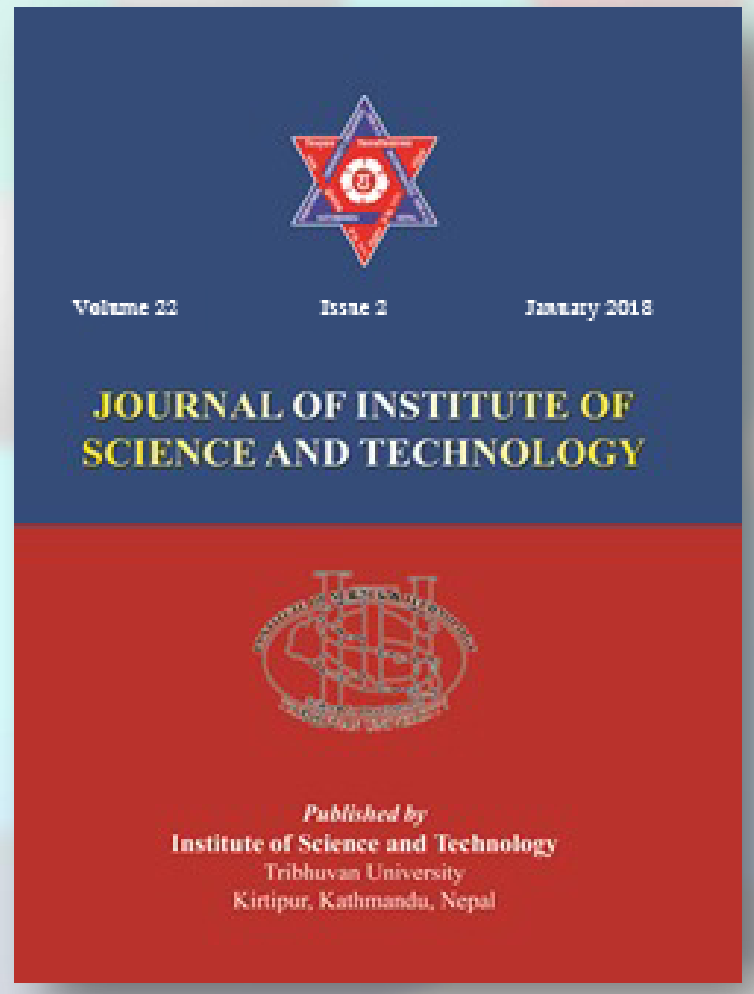

Published by:

Institute of Science and Technology

Tribhuvan University

Kirtipur, Kathmandu, Nepal 


\title{
STRUCTURE, ELECTRONIC AND VIBRATIONAL STUDY OF 7- METHYL-2,3-DIHYDRO-(1,3)THIAZOLO(3,2-A)PYRIMIDIN-5- ONE BY USING DENSITY FUNCTIONAL THEORY
}

\author{
Bhawani Datt Joshi $^{1^{*}}$, Janga Bahadur Khadka ${ }^{2}$ and Atamram Bhatt ${ }^{2}$ \\ ${ }^{I}$ Department of Physics, Siddhanath Sc, Campus, Tribhuvan University, Mahendranagar, Nepal \\ ${ }^{2}$ Department of Chemistry, Siddhanath Sc, Campus, Tribhuvan University, Mahendranagar, Nepal \\ *Corresponding E-mail: pbdjoshi@gmail.com
}

Received: 20 October, 2017; Revised: 6 November, 2017; Accepted: 7 December, 2017

\begin{abstract}
We have presented molecular structure and vibrational wavenumber assignments of 7-methyl-2,3-dihydro$(1,3)$ thiazolo(3,2-a)pyrimidin-5-one. Both ab initio Hartree-Fock and density functional theory employing $6-311++G(d, p)$ basis set have been used for the calculations. The scaled values of the calculated vibrational frequencies were used for assignments on the basis of potential energy distribution. The structure-activity relation has been interpreted by mapping molecular electrostatic potential surface. Electronic properties have been analyzed by using time dependent density functional theory (TD-DFT) for both gaseous and solvent phase. The calculated HOMO (highest occupied molecular orbital) and LUMO (lowest unoccupied molecular orbital) energy values show that the charge transfer occurs within the molecule.
\end{abstract}

Keywords: MeTPDN, DFT, Vibrational spectroscopy, HOMO and LUMO.

\section{INTRODUCTION}

In recent years, there is an urgent need to develop new antimicrobial drugs with potent activities in order to overcome the global problem of bacterial drug resistance. Heterocyclic compounds containing pyrimidine moiety are of great interest because they constitute an important class of natural and non-natural products, many of which exhibit useful biological activities and clinical applications (Bradley et al., 2007; Panlilio et al., 1992; Brown, 1984; Elderfield, 1957). Electronrich nitrogen heterocycles and sulphur compounds play an important role in diverse biological activities. Thiazolo(3,2-a)pyrimidine derivatives are known for their broad spectrum of biological activities such as potential purine antagonists and antioxidants (El-Bayouki \& Basyouni, 2010; Nagarajaiah et al., 2012). They exhibit antiinflammatory (Tozkoparan et al., 1999), antihypertensive (Jeanneau-Nicolle et al., 1992), antimicrobial (Jachak et al., 2005), antiviral (Mohamed et al., 2010), antifungal (Pan et al., 2011), antitumor (Flefel et al., 2007; Al-Omary et al., 2012), anti-HIV (Danel et al., 1998), antitubercular (Geist et al., 2010), calcium channel blocking (Balkan et al., 1992; Cai et al., 2015) etc. as their common activities.

Park et al. (2013), designed and synthesized the oxazolopyridine and thiazolopyridine derivatives, and biologically evaluated their inhibitory activities against monoamine oxidase B (MAO-B) with greater optimal therapeutic potential towards Parkinson's disease. Recently, Cai et al. (2015), reported antibacterial and antitubercular activities of some of the S-alkylated pyrimidine derivatives. Literature reveals that many synthesis and structure-activity related works on these pyrimidine derivatives had been reported, but their vibrational analysis has still not been studied. So, the aim of present study was to fully determine the molecular structure, vibrational modes and the absorption bands of 7-methyl-2,3-dihydro-(1,3)thiazolo(3,2a)pyrimidin-5-one (MeTPDN) theoretically. Both Raman and infrared (IR) are the traditional spectroscopic methods for non-destructive characterization of substances (Chamers \& Griffiths, 2002). Along with the quantum chemical studies, the equilibrium geometry, harmonic vibrational wavenumbers, molecular electrostatic potential surfaces, absolute Raman scattering 
activities and IR absorption intensities have been calculated to support our wavenumber assignments using both $a b$ initio Hartree-Fock (HF) and density functional theory (DFT) (Hohenberg \& Kohn, 1964; Jha et al., 2018; Kumar et al., 2017; Govindarajan et al., 2012). Frontier levels energy gap $(\Delta \mathrm{E})$, dipole moments and the total energy has been obtained from the optimized geometry of the molecule. Most of the calculations have been performed for a single (or isolated) molecule in the gaseous system.

\section{MATERIALS AND METHODS \\ Computational details}

The DFT calculations were mainly carried out on the framework of Becke's three parameter (local, non-local, Hartree-Fock) hybrid exchange functional with Lee-yang-Parr correlation functional (B3LYP) (Casida \& Chong, 1995; Casida et al., 1998; Lee et al., 1998). Molecular structure, vibrational frequencies and energies of the optimized structure of the molecule were calculated using Gaussian 09 (Frisch et al., 2009) program package employing 6-311++G(d,p) basis set (Becke, 1993; Parr \& Yang, 1989). The absolute Raman scattering and IR intensities were calculated at the same level as used for the optimization of geometry. The vibrational assignments of the normal modes were done as by Pualy's recommendation (Pulay et al., 1983) along the internal coordinates employing localized symmetry using GAR2PED (Martin \& Van Aslenoy, 1995). Visualization and confirmation of the calculated data were done by CHEMCRAFT program (Zhurko \& Zhurko, 2005). The graphical presentation of molecular electrostatic potential surface, HOMO LUMO, and the calculated IR and Raman spectra obtained from the Gaussian output were made using Gauss View program (Frisch et al., 2000).

\section{RESULTS AND DISCUSSION}

\section{Geometry optimization}

Using the standard geometric parameters, obtained from structure search data base (https://pubchem.ncbi.), the geometry optimization has been performed as the first task, without using any constraints. These optimized geometric parameters were used for all the other calculations. Calculated vibrational frequency and the equilibrium geometry have been determined by the energy minimization. The ground state optimized molecular structure is shown in the figure 1. The relative energies of the molecule are calculated employing $a b$ initio HF functions and DFT functional. The energy calculated by DFT ($536301.423 \mathrm{kcal} / \mathrm{mol}$ ) is lower showing more stability than the calculated by HF (-534115.669 $\mathrm{kcal} / \mathrm{mol})$.

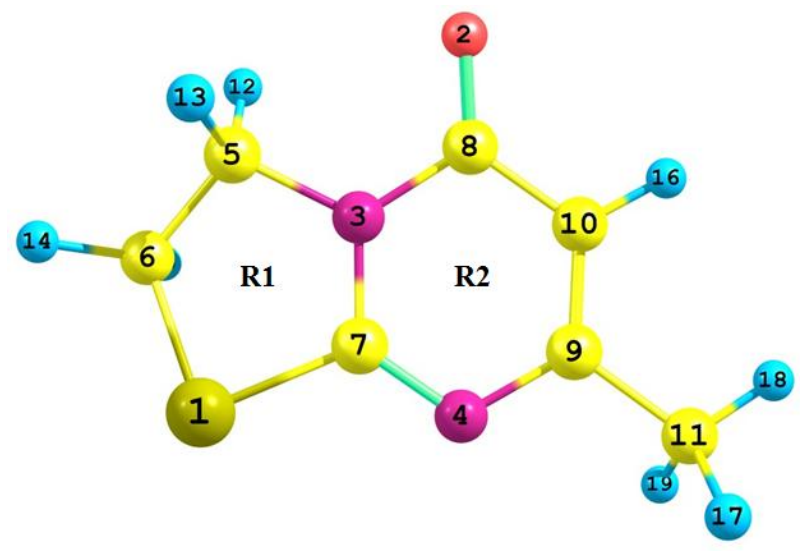

Fig. 1. Optimized structure of MeTPDN molecule.

The enthalpy difference between these two theories is $6.442 \mathrm{kcal} / \mathrm{mol}$. The optimized parameters obtained by DFT method were very close to those obtained by the HF method. In this study, the bond lengths did not differ by more than $0.015 \AA$ except $\mathrm{S} 1-\mathrm{C} 6, \mathrm{O} 2=\mathrm{C} 8, \mathrm{~N} 3-\mathrm{C} 8$ and $\mathrm{N} 4=\mathrm{C} 7$, which differed by $0.022 \AA, \quad 0.0249 \AA, \quad 0.0254 \AA$ and $0.0226 \AA$, respectively. Relative to the bond lengths, both the bond angles and the dihedral angles were very similar (Srivastava et al., 2010) in the two theories.

\section{Molecular electrostatic potential surface}

The molecular electrostatic potential (MEP) in a molecule at any point $\mathrm{r}(\mathrm{x}, \mathrm{y}, \mathrm{z})$ is a force on unit positive charge at that point due to the net charge of the system (electronic and the nuclear charge). It is given by:

$V(r)=\sum_{A=1}^{N} \frac{Z_{A}}{\left|\vec{R}_{A}-\vec{r}\right|}-\int \frac{\rho\left(\vec{r}^{\prime}\right) d r}{\left|\vec{r}^{\prime}-\vec{r}\right|}$

where $Z_{A}$ is the charge on nucleus A located at $R_{A}$ and $\rho\left(r^{\prime}\right)$ is the electron density. The first term is due to the nucleus and the second due to electron cloud.

The MEP is a visualization tool to understand the relative polarization of the molecules (Chidangil et al., 1998). Such surfaces depict the size, shape, charge density, and site of chemical reactivity of the molecules. In the surface generated, negative electrostatic potential (shades of red color) 
corresponds to an attraction of the proton by the concentrated electron density in the molecules (from lone pairs, pi-bonds, etc.) and positive electrostatic potential (shades of blue color) corresponds to repulsion of the proton by the atomic nuclei in the regions where low electron density exists and the nuclear charge is incompletely shielded. The spatial distribution and the values of the electrostatic potential are in fact largely responsible for the binding of a substrate to its receptor binding site. Different values of the

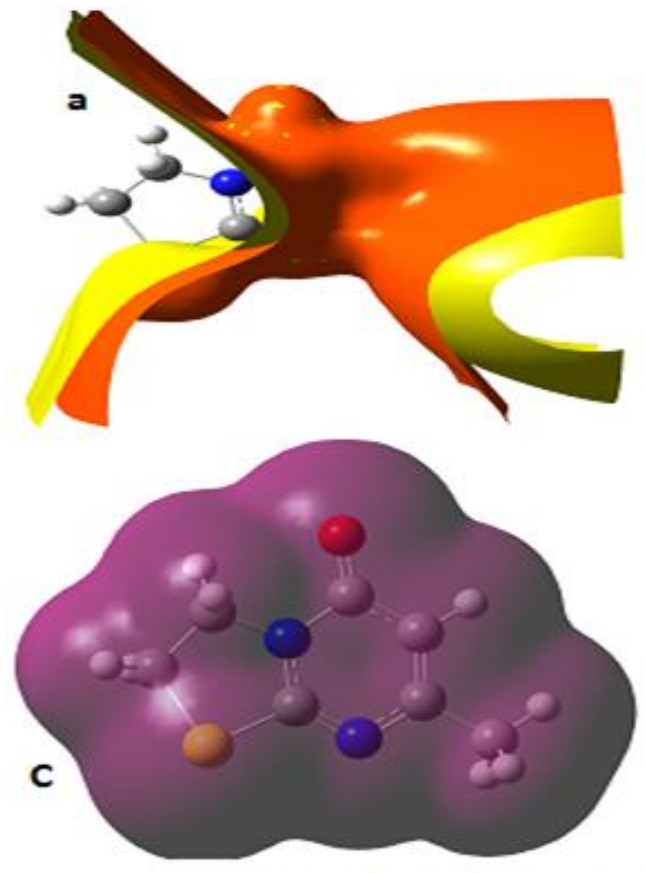

$-5.730 e-2$ electrostatic potential at the surface of a molecule appear with the different colors. The largely white or lighter color shades on the surface indicate that the molecule is mostly non-polar. The potential increases in the order red < orange < yellow < green < blue.

The electrostatic potential surface (ESP), electron density (ED), and the molecular electrostatic potential (MEP) of the molecule mapped with the output obtained by B3LYP/ 6-311++G(d,p) basis are shown in the figures $2(\mathrm{a}-\mathrm{d})$.

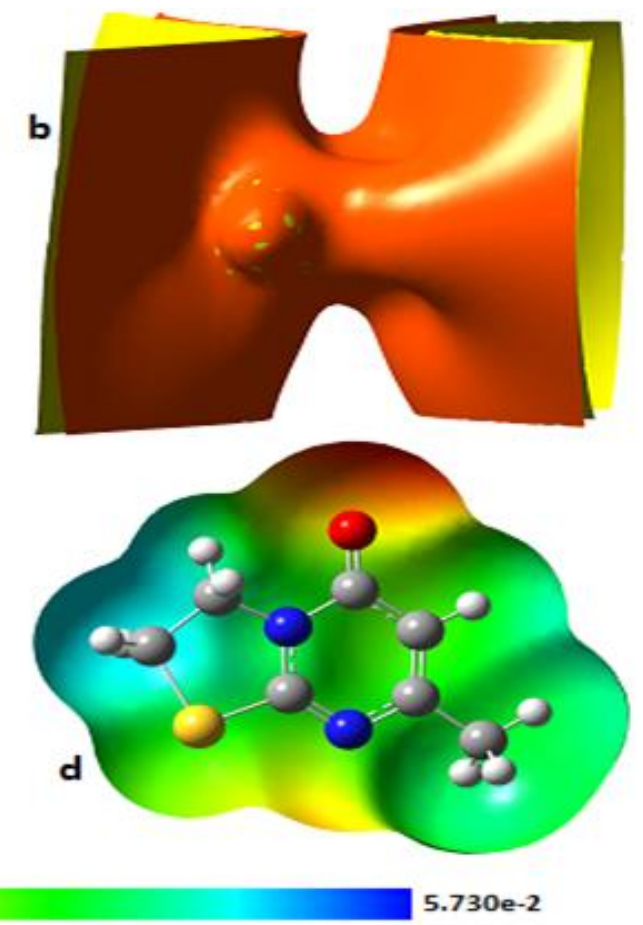

Fig. 2. Graphical representation: (a) electrostatic potential surface in-plane, (b) electrostatic potential surface perpendicular to the plane, (c) electron density, and (d) molecular electrostatic potential (mapped from $-5.730 e-2$ to $5.730 e-2)$.

From the figure, the highest negative potential (red region) is localized over the oxygen atom $\mathrm{O} 2$, as a functional group atom, of pyrimidine ring (R2). A less negative area occurs over the nitrogen atom N4 and sulphur atom S1. Similarly, the lowest potential (blue) is localized over the hydrogen atoms of the ethylene group of the thiazole ring (R1). ED mapping shows the uniform charge distribution over the molecular surface.

\section{Electronic absorption and frontier molecular orbitals (FMOs)}

In order to understand the electronic transitions in terms of energies and oscillator strengths, the time dependent density functional theory (TDDFT)/6-31G (Petersson \& Allaham, 1991) calculations were performed in the gaseous phase as well as in the solvent (EtOH) environment (integral equation formalism polarizable continuum model, IEF-PCM model) (Mishra et al., 2015, Perepichka \& Bryce, 2005). The theoretical UV-vis absorption spectra are shown in the figure 3. Both the frontier molecular orbitals (FMOs), HOMO and LUMO are the main orbitals taking part in the chemical reaction (Singh et al., 2012). Energy difference between these two orbitals is the principal factor for determining the reactivity of the system. 


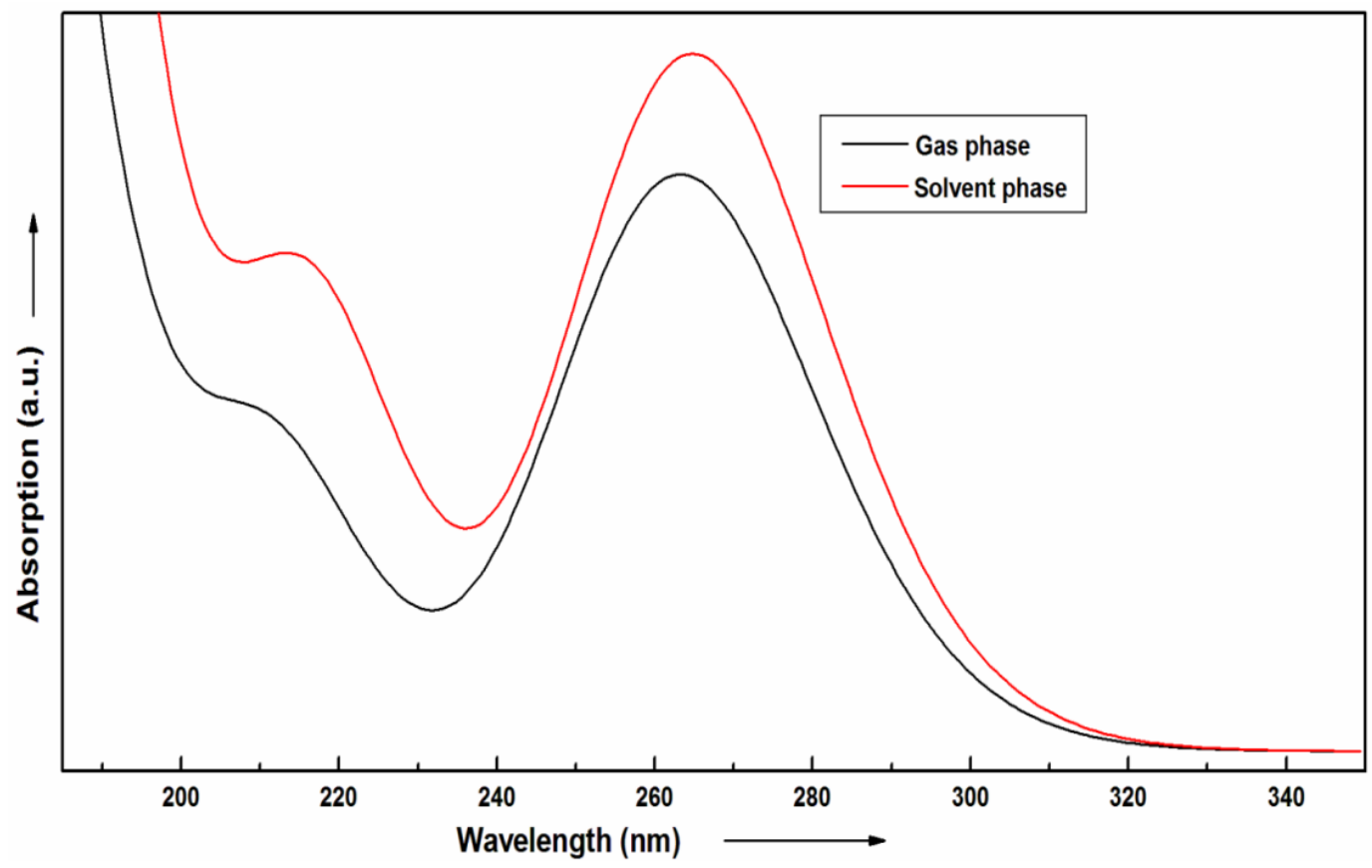

Fig. 3. Theoretical $U V$-vis spectra in the ranges 180-350 $\mathrm{nm}$.

To understand the electronic transitions, positions of experimental absorption peaks, calculated wavelengths $\left(\lambda_{\max }\right)$, vertical excitation energies, oscillator strengths (f), dipole moments, and excitation transition with spectral assignments for gas and solvent environment were carried out, which is given in Table 1. From the table, the main dipole transition in gas phase occurs at $264.70 \mathrm{~nm}(\mathrm{H} \rightarrow \mathrm{L})$ with the oscillator strength 0.1246 . Another strong transition is at $211.27 \mathrm{~nm}$
$(\mathrm{H} \rightarrow \mathrm{L}+1)$ with the oscillator strength 0.0708 . Similarly, in solvent phase, the transitions are centered at $265.14 / 216.21 \mathrm{~nm}(\mathrm{H} \rightarrow \mathrm{L} / \mathrm{H} \rightarrow$ L+1) with the oscillator strengths 0.1726 / 0.1096 , respectively. It was clearly visible that both in gaseous and solvent phase in HOMO as well as in LUMO, the charge was mainly accumulated over the rings. The plots are shown in the figure 4 . The main transition types occurring are $\mathrm{n} \rightarrow \pi^{*}$ and $\pi \rightarrow \pi^{*}$.

Table 1: Electronic transitions, absorption wavelength $\lambda_{\max }(\mathrm{nm})$, excitation energy $(\mathrm{eV})$, oscillator strengths (f), frontier orbital energies (eV) and dipole moment, $\mu$ (Debye).

\begin{tabular}{|c|c|c|c|c|c|c|c|c|}
\hline \multirow{2}{*}{$\begin{array}{l}\text { Excited } \\
\text { states }\end{array}$} & \multicolumn{4}{|c|}{ Gas phase } & \multicolumn{4}{|c|}{ Solvent (EtOH) phase } \\
\hline & Transitions & $\lambda$ & $\mathbf{e V}$ & $\begin{array}{l}\text { Oscillator } \\
\text { strength }\end{array}$ & $\lambda$ & eV & $\begin{array}{l}\text { Oscillator } \\
\text { strength }\end{array}$ & Transitions \\
\hline 1 & $\mathrm{H} \rightarrow \mathrm{L}$ & 264.70 & 4.6839 & 0.1246 & 265.14 & 4.6761 & 0.1726 & $\mathrm{H} \rightarrow \mathrm{L}$ \\
\hline 2 & $\mathrm{H}-1 \rightarrow \mathrm{L}$ & 256.39 & 4.8357 & 0.0203 & 246.68 & 5.0262 & 0.0042 & $\mathrm{H}-2 \rightarrow \mathrm{L}$ \\
\hline 3 & $\mathrm{H}-3 \rightarrow \mathrm{L}$ & 247.37 & 5.0122 & 0.0036 & 228.76 & 5.4199 & 0.0041 & $\mathrm{H}-1 \rightarrow \mathrm{L}$ \\
\hline 4 & $\mathrm{H}-2 \rightarrow \mathrm{L}$ & 227.86 & 5.4413 & 0.0073 & 213.95 & 5.7950 & 0.0017 & $\mathrm{H}-2 \rightarrow \mathrm{L}+1$ \\
\hline \multirow[t]{2}{*}{5} & $\mathrm{H} \rightarrow \mathrm{L}+1$ & 211.27 & 5.8685 & 0.0708 & 216.21 & 5.7345 & 0.1096 & $\mathrm{H} \rightarrow \mathrm{L}+1$ \\
\hline & $\mathrm{E}_{\text {Номо }}(\mathrm{eV})$ & & $\mathrm{E}_{\text {LUMO }}$ & & $\Delta E(\mathrm{eV})$ & & (D) & \\
\hline Gas & -6.370298 & & -1.1618 & & 5.208452 & & 1.9434 & \\
\hline $\mathrm{EtOH}$ & -6.354760 & & -1.0752 & & 5.279501 & & 2.7012 & \\
\hline
\end{tabular}



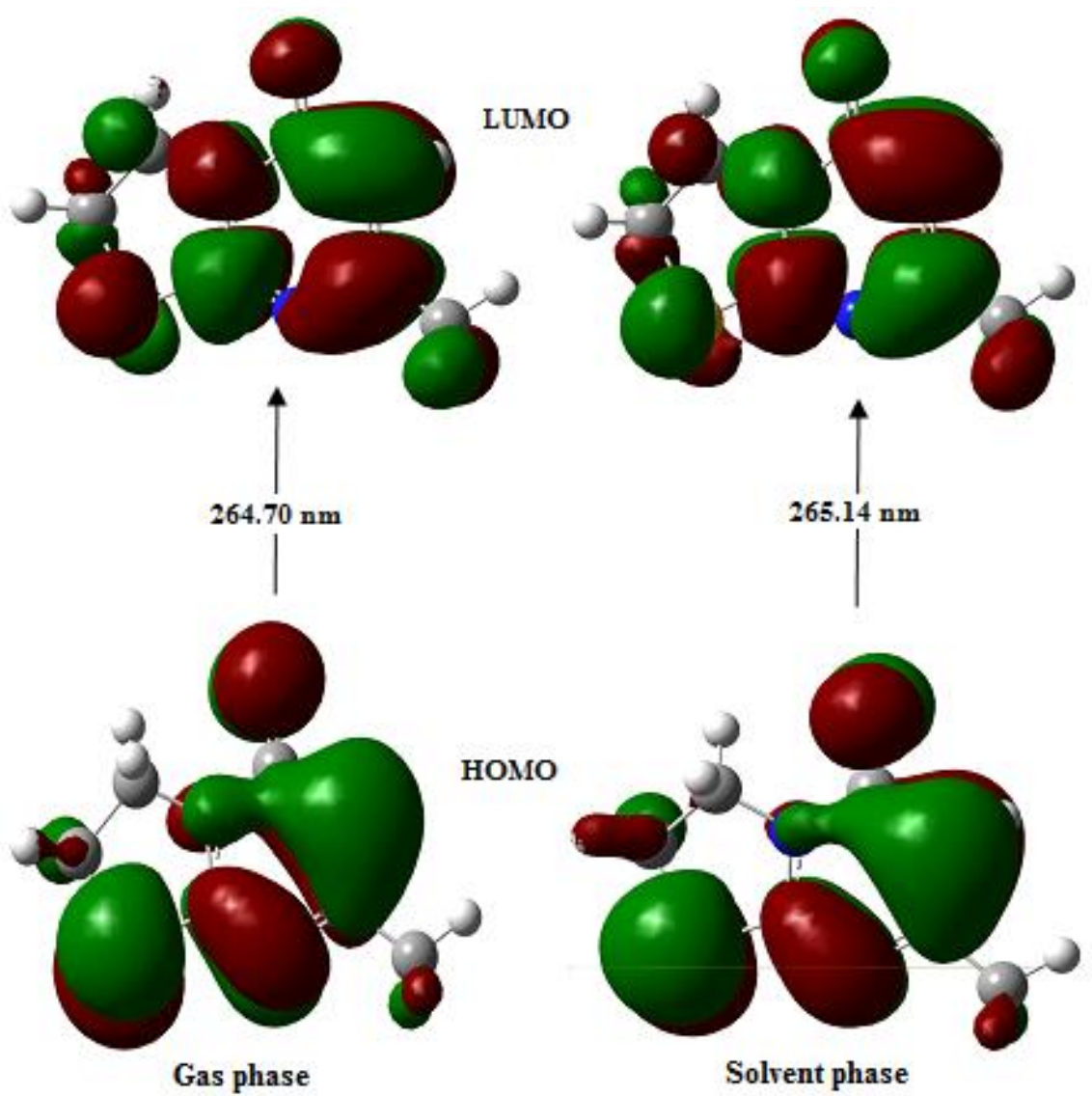

Fig. 4. HOMO-LUMO plots in the gas and solvent phases.

\section{Vibrational spectrum}

The number of atoms in this molecule is 19 and it gives 51 (3N-6, $\mathrm{N}$ number of atom) number of vibrations. All the vibrations are both Raman and IR active. DFT calculations yield Raman scattering amplitudes which cannot be taken directly to be the Raman intensities. The Raman scattering cross section, $\partial \sigma / \partial \Omega$, which are proportional to Raman intensity may be calculated from Raman scattering amplitude and predicted wavenumbers for each normal mode using the relationship (Guirgis et al., 2003; Polavarapu, 1990):

$\frac{\partial \sigma_{j}}{\partial \Omega}=\left(\frac{2^{4} \pi^{4}}{45}\right)\left(\frac{\left(v_{0}-v_{j}\right)^{4}}{1-\exp \left[\frac{-h c v_{j}}{k T}\right]}\right)\left(\frac{h}{8 \pi^{2} c v_{j}}\right) S_{j}$

where $S_{\mathrm{j}}$ and $v_{\mathrm{j}}$ are the scattering activities and the predicted wavenumbers, respectively of the $j^{\text {th }}$ normal mode, $v_{0}$ is the wavenumber of Raman excitation line and $h, c$ and $k$ are universal constants.

Since, the DFT and HF vibrational wavenumbers are known to be higher than the actual values due to neglect of anharmonicity effects, they were scaled down by the wavenumber linear scaling procedure $(\mathrm{WLS})\left(v_{\text {obs }}=\left(1.0087-0.0000163 v_{\text {calc }}.\right) v_{\text {calc }} \mathrm{cm}^{-1}\right)$ of Yoshida et al., 2002. Comparison of the wavenumbers shows that the DFT methods give smaller value of the wavenumbers than the HF due to inclusion of the electron correlation in the first. The wavenumbers, intensities and the PED distributions obtained by HF and DFT methods with $6-311++\mathrm{G}(\mathrm{d}, \mathrm{p})$ basis set are listed in the Table 2. Calculated FT-IR and Raman spectra are shown in the figures $5 \& 6$. The assignments of some selected mode of vibration are discussed below:

\section{Methyl group vibrations}

Methyl $\left(\mathrm{CH}_{3}\right)$ group has several modes associated with it, such as symmetric and asymmetric stretches, bends, rocks, and torsional modes. There is a methyl group attached to the pyrimidine ring as a functional group as shown in the figure 1. The asymmetric stretching of $\mathrm{CH}_{3}$ was predicted at 2993 and $2960 \mathrm{~cm}^{-1}$ with medium intensity in the Raman and weak in the IR spectra. The symmetric stretching related to this mode corresponds at 2911 
$\mathrm{cm}^{-1}$ with strong intensity of 262 arb. units (i.e., $\AA^{4} / \mathrm{amu}$ ) in the Raman spectrum. Asymmetric and symmetric stretches were predicted at 1457 / 1451 and $1404 / 1368 \mathrm{~cm}^{-1}$, respectively. The mixed rocking vibration of $\mathrm{CH}_{3}$ was calculated at 1052 and $1038 \mathrm{~cm}^{-1}$.

Table 2: Calculated FT-IR and FT-Raman wavenumbers $\left(\mathrm{cm}^{-1}\right)$ with their intensities.

\begin{tabular}{|c|c|c|c|c|c|}
\hline Un & & aled & & & Potential energy distribution \% \\
\hline DFT & $\mathrm{HF}$ & DFT & $(\mathbf{k m} / \mathbf{m o l})$ & (A“/amu) & \\
\hline 3211 & 3222 & 3071 & 1.064 & 119.350 & $\mathrm{R} 2(\mathrm{v}(\mathrm{CH}))(99)$ \\
\hline 3140 & 3150 & 3007 & 4.251 & 99.065 & $\mathrm{R} 1\left(\mathrm{v}_{\mathrm{a}}\left(\mathrm{CH}_{2}\right)\right)(99)$ \\
\hline 3125 & 3139 & 2993 & 15.779 & 67.718 & $\mathrm{R} 2\left(\mathrm{v}_{\mathrm{a}}\left(\mathrm{CH}_{3}\right)\right)(99)$ \\
\hline 3122 & 3121 & 2990 & 3.779 & 83.801 & $\mathrm{R} 1\left(\mathrm{v}_{\mathrm{a}}\left(\mathrm{CH}_{2}\right)\right)(99)$ \\
\hline 3089 & 3096 & 2960 & 7.990 & 89.728 & $\mathrm{R} 2\left(\mathrm{v}_{\mathrm{a}}\left(\mathrm{CH}_{3}\right)\right)(99)$ \\
\hline 3074 & 3086 & 2947 & 15.390 & 120.957 & $\mathrm{R} 1\left(\mathrm{v}_{\mathrm{s}}\left(\mathrm{CH}_{2}\right)\right)(97)$ \\
\hline 3043 & 3069 & 2918 & 18.871 & 140.985 & $\mathrm{R} 1\left(\mathrm{v}_{\mathrm{s}}\left(\mathrm{CH}_{2}\right)\right)(98)$ \\
\hline 3035 & 3043 & 2911 & 10.620 & 262.026 & $\mathrm{R} 2\left(\mathrm{v}_{\mathrm{s}}\left(\mathrm{CH}_{3}\right)\right)(100)$ \\
\hline 1739 & 1867 & 1705 & 665.167 & 40.024 & $\mathrm{R} 2(\mathrm{v}(\mathrm{C}=\mathrm{O})(66)+\mathrm{v}(\mathrm{CC})(13))$ \\
\hline 1627 & 1764 & 1598 & 178.614 & 5.162 & $\mathrm{R} 2(\mathrm{v}(\mathrm{C}=\mathrm{C})(37)+v(\mathrm{~N}=\mathrm{C})(22)+\mathrm{v}(\mathrm{C}=\mathrm{O})(9))+\mathrm{R} 1(\mathrm{v}(\mathrm{NC}))(6)$ \\
\hline 1553 & 1672 & 1528 & 406.538 & 66.949 & $\mathrm{R} 2(\mathrm{v}(\mathrm{N}=\mathrm{C})(39)+\mathrm{v}(\mathrm{C}=\mathrm{C})(19)+\mathrm{v}(\mathrm{NC})(7))+\mathrm{R} 1\left(\delta_{\text {ring }}\right)(6)$ \\
\hline 1514 & 1616 & 1489 & 40.2653 & 7.579 & $\mathrm{R} 1\left(\delta\left(\mathrm{CH}_{2}\right)\right)(92)$ \\
\hline 1491 & 1588 & 1468 & 13.400 & 10.574 & $\mathrm{R} 1\left(\delta\left(\mathrm{CH}_{2}\right)\right)(95)$ \\
\hline 1480 & 1570 & 1457 & 29.333 & 19.431 & $\mathrm{R} 2\left(\delta_{\mathrm{a}}{ }_{\mathrm{a}}\left(\mathrm{CH}_{3}\right)\right)(80)$ \\
\hline 1473 & 1564 & 1451 & 8.594 & 8.633 & $\mathrm{R} 2\left(\delta_{\mathrm{a}}\left(\mathrm{CH}_{3}\right)(92)+\rho\left(\mathrm{CH}_{3}\right)(6)\right)$ \\
\hline 1425 & 1540 & 1404 & 132.119 & 20.906 & $\mathrm{R} 2\left(\delta_{\mathrm{s}}\left(\mathrm{CH}_{3}\right)(36)+\mathrm{v}(\mathrm{NC})(15)+\mathrm{v}(\mathrm{C} 9 \mathrm{C} 11)(14)\right)+\mathrm{R} 1(\mathrm{v}(\mathrm{NC})(8))$ \\
\hline 1408 & 1515 & 1388 & 43.612 & 3.280 & $\mathrm{R} 1\left(\omega\left(\mathrm{CH}_{2}\right)(34)+v(\mathrm{NC})(14)\right)+\mathrm{R} 2\left(\delta_{\mathrm{s}}\left(\mathrm{CH}_{3}\right)\right)(32)$ \\
\hline 1387 & 1482 & 1368 & 21.979 & 9.202 & $\mathrm{R} 2\left(\delta_{\mathrm{s}}\left(\mathrm{CH}_{3}\right)(24)+\mathrm{v}(\mathrm{NC})(17)+\delta_{\text {in }}(\mathrm{CH})(15)\right)+\mathrm{R} 1\left(\omega\left(\mathrm{CH}_{2}\right)\right)(15)$ \\
\hline 1321 & 1424 & 1304 & 21.714 & 11.912 & $\mathrm{R} 1\left(\omega\left(\mathrm{CH}_{2}\right)(36)+\gamma\left(\mathrm{CH}_{2}\right)(34)+v(\mathrm{NC})(10)\right)$ \\
\hline 1289 & 1399 & 1273 & 2.813 & 13.193 & $\mathrm{R} 1\left(\omega\left(\mathrm{CH}_{2}\right)(45)+\mathrm{v}(\mathrm{NC})(31)\right)+\mathrm{R} 2(\mathrm{v}(\mathrm{N}=\mathrm{C}))(4)$ \\
\hline 1250 & 1356 & 1236 & 17.295 & 11.912 & $\mathrm{R} 1\left(\gamma\left(\mathrm{CH}_{2}\right)(23)+\omega\left(\mathrm{CH}_{2}\right)(18)+v(\mathrm{NC})(8)\right)+\mathrm{R} 2(\mathrm{v}(\mathrm{N}=\mathrm{C})(5))$ \\
\hline 1224 & 1308 & 1210 & 9.654 & 10.684 & $\mathrm{R} 2\left(\delta_{\text {in }}(\mathrm{CH})(47)+v(\mathrm{C} 9 \mathrm{C} 11)(12)+\delta_{\text {trig }}(9)\right)$ \\
\hline 1197 & 1294 & 1184 & 26.883 & 4.874 & $\mathrm{R} 1\left(\gamma\left(\mathrm{CH}_{2}\right)(45)+\omega\left(\mathrm{CH}_{2}\right)(17)+\mathrm{v}(\mathrm{NC})(9)+\mathrm{v}(\mathrm{CC})(8)+\mathrm{R} 2\left(\delta_{\text {trig }}\right)(6)\right.$ \\
\hline 1183 & 1276 & 1170 & 47.869 & 3.560 & $\mathrm{R} 1\left(\gamma\left(\mathrm{CH}_{2}\right)(29)+v(\mathrm{NC})(8)+\delta_{\text {ring }}^{\prime}(5)\right)+\mathrm{R} 2\left(v(\mathrm{NC})(18)+\delta_{\text {trig }}(9)\right)$ \\
\hline 1130 & 1198 & 1119 & 24.559 & 0.799 & $\mathrm{R} 2(\mathrm{v}(\mathrm{CC})(30)+\mathrm{v}(\mathrm{C} 9 \mathrm{C} 11)(12)+\mathrm{v}(\mathrm{NC})(10))+\mathrm{R} 1(\mathrm{v}(\mathrm{NC}))(19)$ \\
\hline 1061 & 1148 & 1052 & 3.119 & 0.549 & $\mathrm{R} 2\left(\rho\left(\mathrm{CH}_{3}\right)(69)+\mathrm{oop}(\mathrm{C} 9 \mathrm{C} 11)(14)+\delta_{\mathrm{a}}\left(\mathrm{CH}_{3}\right)(5)+\mathrm{oop}(\mathrm{CH})(5)\right)$ \\
\hline 1047 & 1130 & 1038 & 3.006 & 2.503 & $\begin{array}{l}\mathrm{R} 2\left(\rho^{\prime}\left(\mathrm{CH}_{3}\right)(31)+\delta_{\text {trig }}(12)+\delta_{\text {in }}(\mathrm{CH})(7)+\mathrm{v}(\mathrm{NC})(7)+\mathrm{v}(\mathrm{C}=\mathrm{C})(6)+\right. \\
\mathrm{R} 1\left(\rho\left(\mathrm{CH}_{2}\right)\right)(14)\end{array}$ \\
\hline 1034 & 1116 & 1025 & 7.680 & 2.712 & $\mathrm{R} 1\left(\rho\left(\mathrm{CH}_{2}\right)\right)(50)+\gamma\left(\mathrm{CH}_{2}\right)(12)+\mathrm{R} 2\left(\rho^{\prime}\left(\mathrm{CH}_{3}\right)\right)(20)$ \\
\hline 996 & 1074 & 988 & 7.185 & 3.228 & $\begin{array}{l}\mathrm{R} 2\left(v(\mathrm{NC})(27)+\delta_{\text {trig }}(12)+\rho^{\prime}\left(\mathrm{CH}_{3}\right)(11)\right)+\mathrm{R} 1\left(\gamma\left(\mathrm{CH}_{2}\right)(8)+\delta^{\prime}{ }_{\text {ring }}(7)+\right. \\
\left.\rho\left(\mathrm{CH}_{2}\right)(6)\right)\end{array}$ \\
\hline 988 & 1046 & 981 & 1.067 & 1.562 & $\mathrm{R} 1(\mathrm{v}(\mathrm{CC}))(71)+\mathrm{R} 2(\mathrm{v}(\mathrm{CC}))(14)$ \\
\hline 911 & 976 & 906 & 9.587 & 6.852 & $\begin{array}{l}\mathrm{R} 1\left(v(\mathrm{SC})(22)+\rho\left(\mathrm{CH}_{2}\right)(11)\right)+\mathrm{R} 2\left(\mathrm{v}(\mathrm{NC})(17)+\delta^{\prime}{ }_{\mathrm{a}}(17)+\right. \\
v(\mathrm{C} 9 \mathrm{C} 11)(12))\end{array}$ \\
\hline
\end{tabular}




\begin{tabular}{|c|c|c|c|c|c|}
\hline 877 & 947 & 872 & 3.808 & 1.354 & $\begin{array}{l}\mathrm{R} 1\left(\rho\left(\mathrm{CH}_{2}\right)(41)+\delta_{\text {ring }}^{\prime}(11)+\mathrm{v}(\mathrm{SC})(9)+\mathrm{v}(\mathrm{NC})(5)\right)+ \\
\mathrm{R} 2\left(\mathrm{v}(\mathrm{NC})(8)+\mathrm{v}(\mathrm{C} 9 \mathrm{C} 11)(6)+\delta_{\text {trig }}(5)\right)\end{array}$ \\
\hline 851 & 919 & 846 & 28.339 & 0.583 & $\mathrm{R} 2(\operatorname{oop}(\mathrm{CH})(72)+\operatorname{oop}(\mathrm{C}=\mathrm{O})(14)+\operatorname{puck}(7))$ \\
\hline 767 & 841 & 764 & 9.040 & 5.245 & $\begin{array}{l}\mathrm{R} 1\left(v(\mathrm{NC})(20)+\rho\left(\mathrm{CH}_{2}\right)(9)+\delta^{\prime}{ }_{\text {ring }}(6)\right)+\mathrm{R} 2(\operatorname{puck}(17)+ \\
\left.\operatorname{oop}(\mathrm{C}=\mathrm{O})(12)+\delta_{\text {trig }}(9)\right)\end{array}$ \\
\hline 747 & 812 & 745 & 6.185 & 1.521 & $\mathrm{R} 2(\operatorname{puck}(38)+\mathrm{oop}(\mathrm{C}=\mathrm{O})(28)+\mathrm{oop}(\mathrm{C} 9 \mathrm{C} 11)(6))+\mathrm{R} 1(\mathrm{v}(\mathrm{NC}))(6)$ \\
\hline 686 & 760 & 685 & 4.141 & 12.191 & $\mathrm{R} 1\left(v(\mathrm{SC})(70)+\delta_{\text {ring }}^{\prime}(12)\right)+\mathrm{R} 1(\rho(\mathrm{CH} 2))(8)$ \\
\hline 665 & 737 & 663 & 0.789 & 0.205 & $\begin{array}{l}\mathrm{R} 2\left(\tau^{\prime}(23)+\mathrm{oop}(\mathrm{C}=\mathrm{O})(19)+\operatorname{puck}(19)+\mathrm{oop}(\mathrm{C} 9 \mathrm{C} 11)(8)\right)+ \\
\tau(\mathrm{N} 3 \mathrm{C} 7)(15)+\mathrm{R} 1(\tau(8)+\end{array}$ \\
\hline 632 & 682 & 631 & 3.660 & 2.683 & $\begin{array}{l}\mathrm{R} 2\left(\delta_{\text {in }}(\mathrm{C}=\mathrm{O})(30)+\delta^{\prime}{ }_{\mathrm{a}}(15)+\delta_{\text {in }}(\mathrm{C} 9 \mathrm{C} 11)(13)\right)+\mathrm{R} 1\left(\delta_{\text {ring }}{ }_{\text {ring }}(10)+\right. \\
\left.\mathrm{v}(\mathrm{NC})(9)+\delta_{\text {ring }}(5)\right)\end{array}$ \\
\hline 577 & 632 & 577 & 2.832 & 3.061 & $\mathrm{R} 2\left(\mathrm{oop}(\mathrm{C} 9 \mathrm{C} 11)(43)+\tau(26)+\rho\left(\mathrm{CH}_{3}\right)(6)\right)+\mathrm{R} 1(\tau)(8)$ \\
\hline 571 & 611 & 570 & 7.826 & 13.523 & $\begin{array}{l}\mathrm{R} 2\left(\delta_{\mathrm{a}}{ }_{\mathrm{a}}(13)+\mathrm{v}(\mathrm{CC})(13)+\delta_{\text {in }}(\mathrm{C}=\mathrm{O})(11)+\mathrm{oop}(\mathrm{C} 9 \mathrm{C} 11)(10)+\right. \\
\left.\mathrm{v}(\mathrm{C} 9 \mathrm{C} 11)(10)+\delta_{\text {trig }}(8)+\tau(5)\right)+\mathrm{R} 1\left(\delta_{\text {ring }}\right)(6)\end{array}$ \\
\hline 537 & 584 & 537 & 0.145 & 0.353 & $\mathrm{R} 1\left(\delta_{\text {ring }}(42)+\delta_{\mathrm{a}}(29)+\mathrm{v}(\mathrm{SC})(11)+\rho\left(\mathrm{CH}_{2}\right)(6)\right)$ \\
\hline 440 & 475 & 441 & 1.072 & 6.991 & $\mathrm{R} 2\left(\delta_{\mathrm{a}}(39)+\mathrm{v}(\mathrm{CC})(5)\right)+\mathrm{R} 1\left(\delta_{\text {ring }}(34)+v(\mathrm{NC})(6)\right)$ \\
\hline 428 & 469 & 429 & 5.397 & 6.381 & $\mathrm{R} 1(\mathrm{v}(\mathrm{SC}))(46)+\mathrm{R} 2\left(\delta_{\mathrm{a}}{ }_{\mathrm{a}}(24)+\delta_{\mathrm{in}}(\mathrm{C} 9 \mathrm{C} 11)(13)+\mathrm{v}(\mathrm{NC})(6)\right)$ \\
\hline 322 & 352 & 323 & 3.929 & 1.269 & $\mathrm{R} 2\left(\delta_{\mathrm{in}}(\mathrm{C}=\mathrm{O})(32)+\delta_{\text {in }}(\mathrm{C} 9 \mathrm{C} 11)(31)+\delta_{\mathrm{a}}(7)+\mathrm{v}(\mathrm{NC})(6)\right)$ \\
\hline 270 & 284 & 271 & 0.352 & 0.583 & $\tau(\mathrm{N} 3 \mathrm{C} 7)(43)+\mathrm{R} 1(\tau)(39)+\mathrm{R} 2(\tau)(10)$ \\
\hline 257 & 277 & 258 & 5.188 & 1.337 & $\mathrm{R} 2\left(\delta_{\text {in }}(\mathrm{C} 9 \mathrm{C} 11)(38)+\delta_{\mathrm{a}}(5)\right)+\mathrm{R} 1\left(\delta_{\text {ring }}(20)+\mathrm{v}(\mathrm{SC})(7)\right)$ \\
\hline 199 & 220 & 200 & 4.846 & 0.354 & $\mathrm{R} 2\left(\tau^{\prime}(53)+\mathrm{oop}(\mathrm{CH})(9)\right)+\mathrm{R} 1\left(\tau^{\prime}\right)(20)+\tau(\mathrm{N} 3 \mathrm{C} 7)(9)$ \\
\hline 183 & 197 & 185 & 0.381 & 0.822 & $\mathrm{R} 1(\tau)(49)+\mathrm{R} 2\left(\mathrm{oop}(\mathrm{CH})(14)+\operatorname{puck}(13)+\tau^{\prime}(5)\right)$ \\
\hline 131 & 155 & 132 & 0.170 & 0.339 & $\begin{array}{l}\mathrm{R} 2(\operatorname{puck}(30)+\tau(11)+\text { oop }(\mathrm{C} 9 \mathrm{C} 11)(9)+\mathrm{oop}(\mathrm{CH})(6))+ \\
\mathrm{R} 1\left(\tau^{\prime}\right)(24)+\tau(\mathrm{N} 3 \mathrm{C} 7)(11)\end{array}$ \\
\hline 127 & 144 & 128 & 0.225 & 0.286 & $\tau(\mathrm{C} 9 \mathrm{C} 11)(70)+\mathrm{R} 2\left(\tau^{\prime}\right)(13)$ \\
\hline 98 & 106 & 99 & 9.248 & 0.070 & $\mathrm{R} 2(\tau(38)+\operatorname{puck}(5))+\tau(\mathrm{N} 3 \mathrm{C} 7)(29)+\mathrm{R} 1\left(\tau^{\prime}\right)(22)$ \\
\hline
\end{tabular}

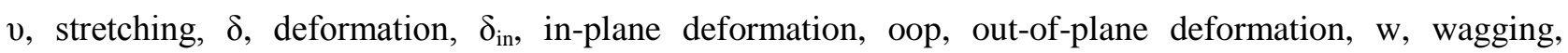
$\rho$, rocking, $\gamma$, twisting and $\tau$, torsion.

\section{Thiazole ring ( $\mathrm{R} 1)$ vibrations}

The methylene $\left(\mathrm{CH}_{2}\right)$ groups are characterized by six fundamental modes of vibration. Out of them symmetric and asymmetric stretch, bending and rocking modes belong to polarized in-plane vibration. Similarly, wagging and twisting modes belong to the depolarized out-of-plane vibration (Joshi et al., 2011). The asymmetric $\mathrm{CH}_{2}$ stretching vibrations are generally observed in the region of 3000-2900 $\mathrm{cm}^{-1}$, while the $\mathrm{CH}_{2}$ symmetric stretch appears in the region $2900-2800 \mathrm{~cm}^{-1}$ (Sajan et al., 2004; Balachandran \& Parimala, 2012). In this study, the asymmetric stretching vibration of $\mathrm{CH}_{2}$ group was calculated at 3007 and $2990 \mathrm{~cm}^{-1}$ while the symmetric stretching vibration was predicted at 2947 and $2918 \mathrm{~cm}^{-1}$. The deformation was predicted at 1489 and $1468 \mathrm{~cm}^{-1}$. Wagging, twisting and rocking vibrations were predicted below 1390 $\mathrm{cm}^{-1}$ as shown in the Table 2 . The mixed SC stretching vibration was calculated at 906, 685 and $429 \mathrm{~cm}^{-1}$. CC stretching was predicted at $981 \mathrm{~cm}^{-1}$.

\section{Pyrimidine ring (R2) vibrations}

The $\mathrm{CH}$ stretching was predicted at $3071 \mathrm{~cm}^{-1}$. The in-plane and out-of-plane bending vibration of this group were predicted at 1210 and $846 \mathrm{~cm}^{-1}$, respectively. The most of the characteristic features of the carboxylic group are observed usually in the region 1700-1800 $\mathrm{cm}^{-1}$ (Banwell \& McCash, 1994). In this study, $\mathrm{C}=\mathrm{O}$ stretching was predicted at 1705 $\mathrm{cm}^{-1}$ which has very strong intensity of 665 arb. units (i.e., $\mathrm{km} / \mathrm{mole}$ ) in the IR spectrum and medium intensity of 40 units in the Raman spectrum. The in-plane bending related to this group modes vibration was calculated at $631 \mathrm{~cm}^{-1}$. 


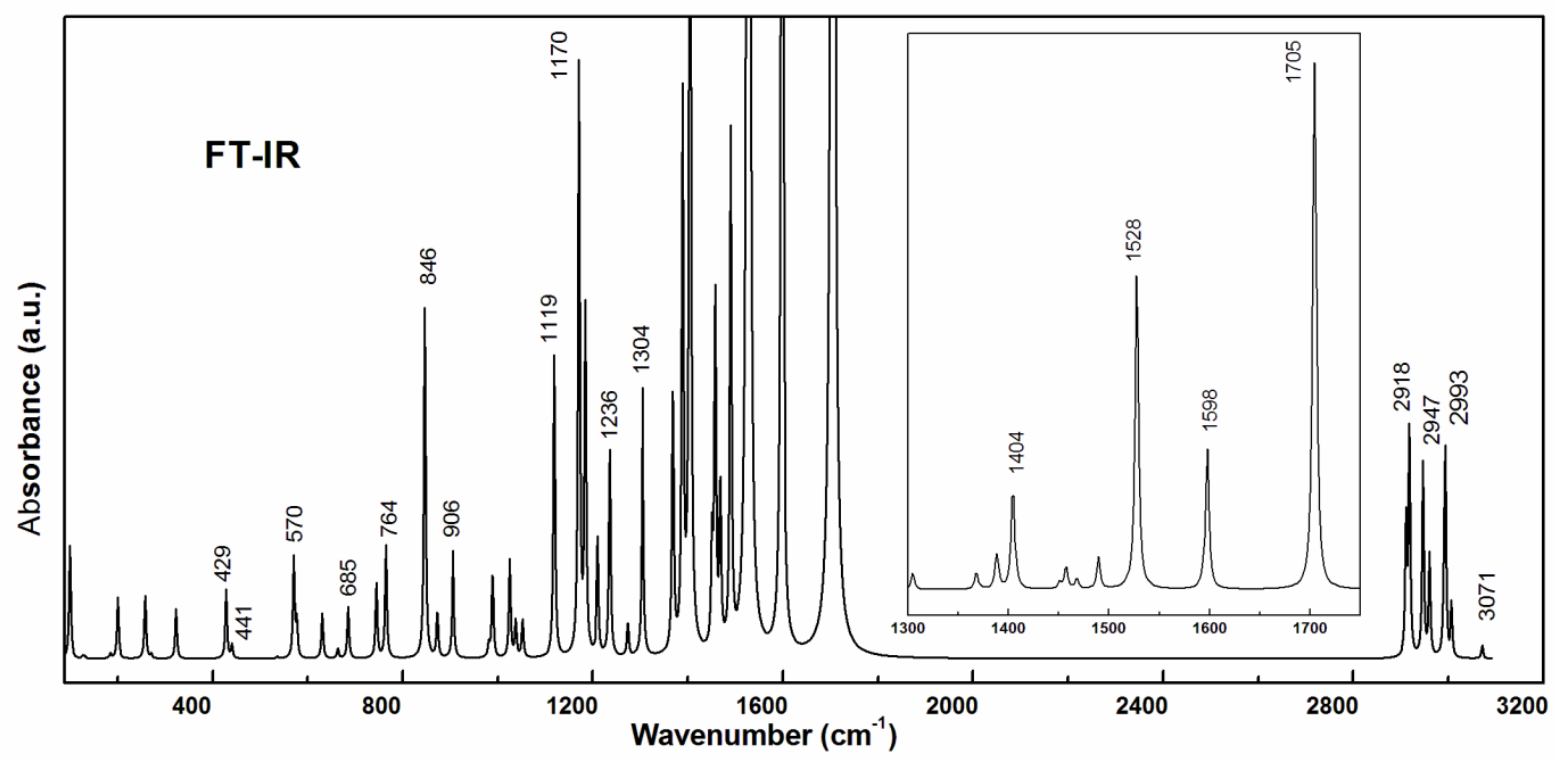

Fig. 5. Calculated FT-IR spectra between the ranges $100-3200 \mathrm{~cm}^{-1}$ (frequency ranges $1300-1800 \mathrm{~cm}^{-1}$ with high absorbance is given in the inset section). Absorbances of selected characteristic modes are assigned.

$\mathrm{C}=\mathrm{C}$ ring stretching was predicted at $1598 \mathrm{~cm}^{-1}$ with strong intensity in the IR spectrum and weak intensity in the Raman spectrum. $\mathrm{N}=\mathrm{C}$ stretching was calculated at $1528 \mathrm{~cm}^{-1}$, which has very strong intensity in the IR spectrum (407 $\mathrm{km} / \mathrm{mole}$ ) and medium intensity in the Raman spectrum $(67 \mathrm{~km} / \mathrm{mole})$. The mixed CC stretching was predicted at $1119 \mathrm{~cm}^{-1}$. Similarly, the NC stretching vibration was predicted at $988 \mathrm{~cm}^{-1}$. The highly mixed ring puckering, deformation, torsion were predicted at 745,741 and $200 \mathrm{~cm}^{-1}$, respectively.

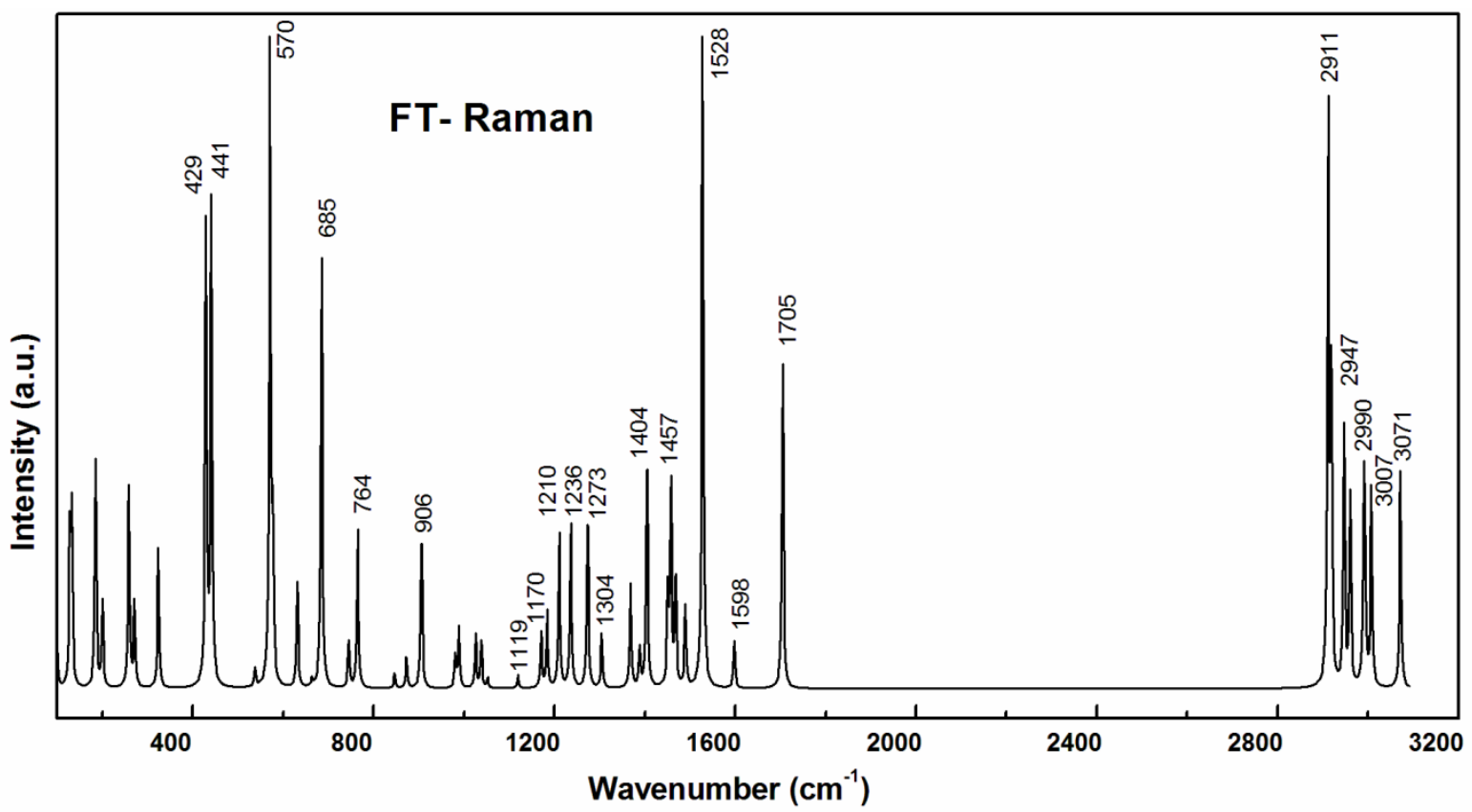

Fig. 6. Calculated FT- Raman spectra between the ranges $100-3200 \mathrm{~cm}^{-1}$ (intensity of selected characteristic modes are assigned). 


\section{CONCLUSION}

We have mainly concentrated to study the wavenumber calculations theoretically. All the assigned 51 modes of vibration are both IR and Raman active. The MEP mapping gives the size, shape, charge density distribution and sites of chemical reactivity of the title molecule which would be a good starting point for studying the detailed potential surface of the molecule. From the HOMO-LUMO plot it is clear that the charge accumulation mainly takes place from HOMO to LUMO both in the gaseous and solvent phases. The gap energy between these two frontier energy levels $5.21 \mathrm{eV}$ (gaseous phase) indicates the high stability of the molecule.

\section{ACKNOWLEDGEMENTS}

BD Joshi would like to thank Brazilian National Council of Scientific and Technological Development $(\mathrm{CNPq})$ and TWAS, the academy of sciences for the developing world for the financial support (CNPq-TWAS Post-Doc fellowship2014/190175/2013-3/FR number: 3240279899) to study Post-Doc at "Universidate Federal do Ceará, CE, Fortaleza, Brazil".

\section{REFERENCES}

Al-Omary, F. A.; Hassan, G. S.; El-Messery, S. M. and El-Subbagh, H. I. (2012). Substituted thiazoles V. Synthesis and antitumor activity of novel thiazolo $(2,3-b)$ quinazoline and pyrido (4,3-d) thiazolo (3,2-a) pyrimidine analogues, European Journal of Medicinal Chemistry, 47: 65-72.

Balachandran, V. and Parimala, K. (2012). Molecular structure, vibrational spectra, NBO analysis, first hyperpolarizability, Journal of Molecular Structure, 1007: 136145.

Balkan, A.; Uma, S.; Ertan, M. and Wiegrebe, W. (1992). Thiazolo (3,2- $\alpha)$-pyrimidine derivatives as calcium antagonists, Pharmazie, 47: 687-688.

Banwell, C. N. and McCash, E. M. (1994). Fundamentals of Molecular Spectroscopy, (fourth ed.), McGraw-Hill International (UK) Limited.

Becke, A. D. (1993). Density-functional thermochemistry. III. The role of exact exchange, The Journal of Chemical Physics, 98: $5648-5652$.
Bradley, J. S.; Guidos, R.; Baragona, S. et al. (2007). Anti-infective research and development-problems, challenges, and solutions. The Lancet Infectious Diseases, 7 (1): 68-78.

Brown, D. J. (1984). Comprehensive Heterocyclic Chemistry, vol. 14 (Edited by A.R. Katritzky and C.W. Rees), Pergamon Press, Oxford, UK.

Cai, D.; Zhang, Z. H.; Chen, Y.; Yan, X. J.; Zou, L. J.; Wang, Y. N. et al. (2015). Synthesis, Antibacterial and Antitubercular Activities of Some 5H-Thiazolo(3,2-a)pyrimidin-5-ones and Sulfonic Acid Derivatives, Molecules, 20: 16419-16434.

Casida, M. E. and Chong, D. P. (1995). Recent Developments in Density Functional Theory, vol. 1, World Scientific, Singapore, Pp. 155.

Casida, M. E.; Casida, K. C. and Salahub, D. R. (1998). Excited-state potential energy curves from time-dependent density-functional theory: A cross section of formaldehyde's ${ }^{1} A_{1}$ manifold. International Journal of Quantum Chemistry, 70: 933-941.

Chamers, J. M. and Griffiths, P. R. (2002). Handbook of Vibrational Spectroscopy, John Wiley and Sons.

Chidangil, S.; Shukla, M. K. and Mishra, P. C. (1998). A Molecular Electrostatic Potential Mapping Study of Some Fluoroquinolone Anti-Bacterial Agents. Journal of Molecular Modeling, 4: 250-258.

Danel, K.; Pedersen, E. B. and Nielsen, C. (1998). Synthesis and anti-HIV-1 activity of novel 2,3-dihydro-7 $H$-thiazolo (3,2-a) pyrimidin7-ones. Journal of Medicinal Chemistry, 41: 191-198.

El-Bayouki, K. A. and Basyouni, W. M. (2010). Thiazolopyrimidines without bridge-head nitrogen: Thiazolo $(4,5-d)$ pyrimidines. Journal of Sulfur Chemistry, 31: 551-590.

Elderfield, R. C. (1957). Heterocyclic Compounds, vol. 6, John Wiley \& Sons, New York, NY, USA.

Flefel, E.; Salama, M.; El-Shahat, M.; El-Hashash, M. and El-Farargy, A. (2007). A novel synthesis of some new pyrimidine and thiazolopyrimidine derivatives for anticancer evaluation. Phosphorus, Sulfur, and Silicon and the Related Elements, 182: 1739-1756. 
Frisch, A.; Nielson, A. B. and Holder, A. J. (2009). Gauss View User Manual, Gaussian Inc, Pittsburgh, P.A.

Frisch, M. J.; Trucks, G. W.; Schlegel, H. B.; Scuseria, G. E.; Cheeseman, J. R.; Robb, M. A.; et al.(2009). GAUSSIAN 09, Revision, Gaussian, Inc., Wallingford, CT.

Geist, J. G.; Lauw, S.; Illarionova, V.; Illarionov, B.; Fischer, M.; Gräwert, T. et al. (2010). Thiazolopyrimidine inhibitors of 2methylerythritol 2,4-cyclodiphosphate synthase (IspF) from mycobacterium tuberculosis and plasmodium falciparum. Chem Med Chem, 5: 1092-1101.

Govindarajan, M.; Karabacak, M.; Suvitha, A. and Periandy, S. (2012). FT-IR, FT-Raman, ab initio, HF and DFT studies, NBO, HOMOLUMO and electronic structure calculations on 4-chloro-3-nitrotoluene. Spectrochimica Acta Part A, 89: 137- 148.

Guirgis, G. A.; Klaboe, P.; Shen, S.; Powell, D. L.; Gruodis, A.; Aleksa, V. et al. (2003). Spectra and structure of silicon-containing compounds. XXXVI-Raman and infrared spectra, conformational stability, ab initio calculations and vibrational assignment of ethyldibromosilane. Journal of Raman Spectroscopy, 34 (4): 322-336.

Hohenberg, P. and Kohn, W. (1964). Inhomogeneous Electron Gas. Physical Review B, 136: 864-871.

Jachak, M. N.; Avhale, A. B.; Tantak, C. D.; Toche, R. B. and Reidlinger, C. (2005). Friedlander condensation of 5-aminopyrazole-4carbaldehydes with reactive-methylene ketones: Synthesis of pyrazolo (3,4-b) pyridines. Journal of Heterocyclic Chemistry, 42: 1311-1319.

Jeanneau-Nicolle, E.; Benoit-Guyod, M.; Namil, A. and Leclerc, G. (1992). New thiazolo (3,2-a) pyrimidine derivatives, synthesis and structure-activity relationships. European Journal of Medicinal Chemistry, 27: 115120.

Jha, O.; Yadav, T. K. and Yadav, R. A. (2018). Structural and vibrational study of a neurotransmitter molecule: Dopamine (4-(2aminoethyl) benzene-1,2-diol), Spectrochimica Acta A, 189: 473-484.

Joshi, B. D.; Srivastava, A.; Tandon, P. and Jain, S. (2011). Molecular structure, vibrational spectra and HOMO, LUMO analysis of yohimbine hydrochloride by density functional theory and $a b$ initio Hartree-Fock calculations. Spectrochimica Acta A, 82: 270- 278.

Kumar, A.; Kumar, R.; Gupta, A.; Tandon, P. and D'silva, E. D. (2017). Molecular structure, nonlinear optical studies and spectroscopic analysis of chalcone derivative (2E)-3-(4(methylsulfanyl) phenyl)-1-(3-bromophenyl) prop-2-en-1-one by DFT calculations. Journal of Molecular Structure, 1150: 166178.

Lee, C.; Yang, W. and Parr, R. G. (1998). Development of the Colic-Salvetti Correlation-Energy Formula into a Functional of the Electron Density. Physical Review B, 37: 785-789.

Martin, J. M. L. and Van Aslenoy, C. (1995). Gar2ped. University of Antwerp.

Mishra, R.; Srivastava, A.; Tandon, P. and Jain, S. (2015). Spectroscopic and quantum chemical analysis of a natural product - Hayatin hydrochloride. Journal of Mololecular Structure, 1093: 101-112.

Mohamed, S. F.; Flefel, E. M.; Amr, A. E. G. E. and El-Shafy, D. N. A. (2010). Anti-HSV-1 activity and mechanism of action of some new synthesized substituted pyrimidine, thiopyrimidine and thiazolopyrimidine derivatives. European Journal of Medicinal Chemistry, 45: 1494-1501.

Nagarajaiah, H.; Khazi, I. and Begum, N. S. (2012). Synthesis, characterization and biological evaluation of thiazolopyrimidine derivatives. Journal of Chemical Sciences, 124: 847-855.

Pan, B.; Huang, R.; Zheng, L.; Chen, C.; Han, S.; $\mathrm{Qu}, \quad \mathrm{D}$. et al. (2011). Thiazolidione derivatives as novel antibiofilm agents: Design, synthesis, biological evaluation, and structure-activity relationships. European Journal of Medicinal Chemistry, 46: 819824.

Panlilio, A. L.; Culver, D. H.; Gaynes, R. P. et al. (1992). Methicillinresistant staphylococcus aureus in U.S. hospitals, 1975-1991. Infection Control and Hospital Epidemiology, 13 (10): 582-586.

Park, H. R.; Kim, J.; Kim, T.; Jo, S.; Yeom, M.; Moon, B. et al. (2013). Oxazolopyridines and thiazolopyridines as monoamine oxidase B inhibitors for the treatment of Parkinson's 
disease. Bioorganic \& Medicinal Chemistry, 21: $5480-5487$.

Parr, R. G. and Yang, W. (1989). Density Functional Theory of Atoms and Molecules, Oxford, New York.

Perepichka, D. F. and Bryce, M. R. (2005). Molecules with Exceptionally Small HOMO-LUMO Gaps. Angewandte Chemie International Edition, 44: 5370-5373.

Petersson, G. A. and Allaham, M. A. (1991). A Complete Basis Set Model Chemistry. II Open- Shell Systems and the Total Energies of the First-Row Atoms. The Journal of Chemical Physics, 94: 6081-6090.

Polavarapu, P. L. (1990). Ab initio vibrational Raman and Raman optical activity spectra. The Journal of Physical Chemistry, 94(21): 8106-8112.

Pulay, P.; Fogarasi, G.; Ponger, G.; Boggs, J. E. and Vargha, A. (1983). Combination of theoretical $a b$ initio and experimental information to obtain reliable harmonic force constants. Scaled Quantum Mechanical (SQM) force fields for glyoxal, acrolein, butadiene, formaldehyde, and ethylene. Journal of American Chemical Society, 105 (24): 7037-7047.

Sajan, D.; Binoy, J.; Pradeep, B.; Venkata Krishna, K.; Kartha, V. B., Joe, I. H. et al. (2004). NIR-FT Raman and infrared spectra and $a b$ initio computations of glycinium oxalate. Spectrochimica Acta A, 60: 173-180.

Singh, R. N.; Kumar, A.; Tiwari, R. K.; Rawat, P.; Verma, D. and Baboo, V. (2012). Synthesis, molecular structure and spectral analysis of ethyl 4-formyl-3,5-dimethyl-1H-pyrrole-2carboxylate thiosemicarbazone: A combined DFT and AIM approach. Journal of Molecular Structure, 1016: 97-108.

Srivastava, A.; Mishra, S.; Tandon, P.; Patel, S.; Ayala, A. P.; Bansal, A. K. et al. (2010). Molecular structure and vibrational spectroscopic analysis of an antiplatelet drug, clopidogrel hydrogen sulphate (form 2) - A combined experimental and quantum chemical approach. Journal of Molecular Structure, 964: 88-96.

Tozkoparan, B.; Ertan, M.; Kelicen, P. and Demirdamar, R. (1999). Synthesis and antiinflammatory activities of some thiazolo (3,2-a) pyrimidine derivatives. Farmaco, 54: 588-593.

Yoshida, H.; Takeda, K.; Okamura, J.; Ehara, A. and Matsurra, H. (2002). A new approach to vibrational analysis of large molecules by density functional theory: wavenumberlinear scaling method. The Journal of Physical Chemistry A, 106 (14): 3580-3586.

Zhurko, G. A. and Zhurko, D. A. (2005). Chemcraft - 64 bit, US version (Online) <http://www.chemcraftprog.com>. 